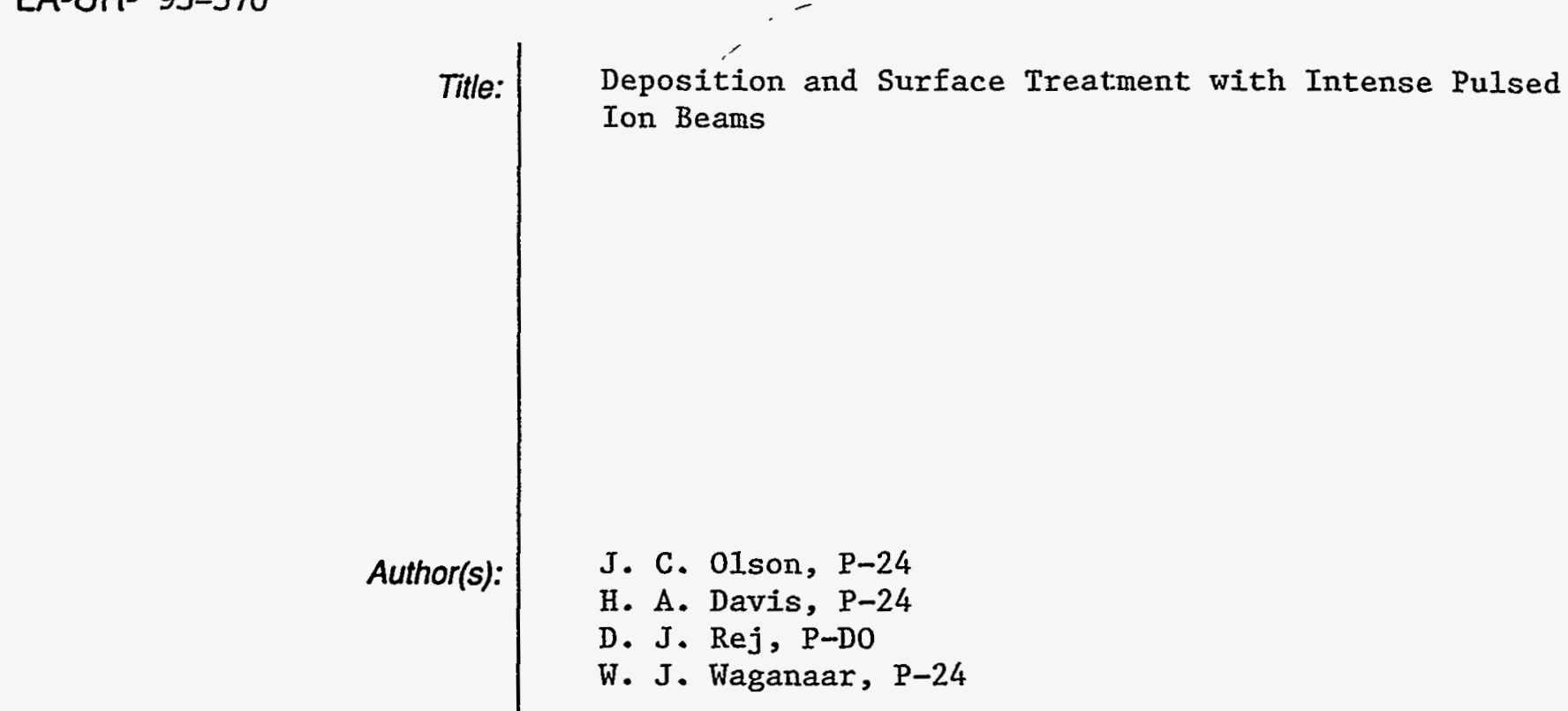

Submitted to:

124th TMS Annual Meeting \& Exhibition

RECHIED

MAR 101995

OSTI

Los Alamos

NATIONAL LABORATORY

February 12-16, 1995

Las Vegas, NV

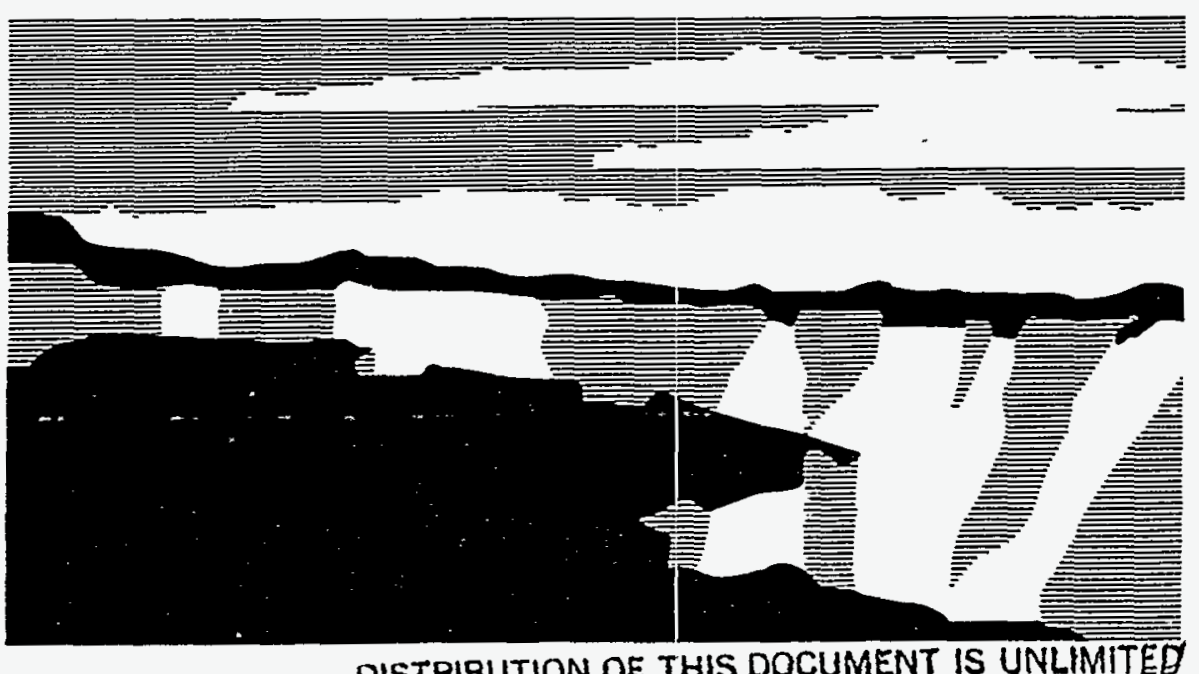

Los Alamos National Laboratory, an affirmative action/equal opportunity emplóyer, is operated by the University of Calfitornia for the U.S. Department of Energy under contract W.7405-ENG-36. By acceptance of this article. the publisher recognizes that the U.S. Government ritains a nonexclusive, royalty-free license to publish or reproduce ine Dublished form of this contnbution. or to allow others to do so. for U.S. Government purposes. The Los Alamos National Laboratory requests that the publisher identify this article as work performed under the auspices of the U.S. Deparment of Energy. 


\section{DISCLAIMER}

This report was prepared as an account of work sponsored by an agency of the United States Government. Neither the United States Government nor any agency thereof, nor any of their employees, make any warranty, express or implied, or assumes any legal liability or responsibility for the accuracy, completeness, or usefulness of any information, apparatus, product, or process disclosed, or represents that its use would not infringe privately owned rights. Reference herein to any specific commercial product, process, or service by trade name, trademark, manufacturer, or otherwise does not necessarily constitute or imply its endorsement, recommendation, or favoring by the United States Government or any agency thereof. The views and opinions of authors expressed herein do not necessarily state or reflect those of the United States Government or any agency thereof. 


\section{DISCLAIMER}

Portions of this document may be illegible in electronic image products. Images are produced from the best available original document. 


\title{
Deposition and Surface Treatment with Intense Pulsed Ion
}

\section{Beams}

\author{
J. C. Olson. H. A. Davis, D. J. Rej and W. J. Waganaar \\ Los Alamos National Laboratory, Los Alamos, NM
}

\author{
R. W. Stinnett and D. C. McIntyre \\ Sandia National Laboratories, Albuquerque, NM
}

(February 8,1995$)$

\begin{abstract}
Intense pulsed ion beams $(500 \mathrm{keV}, 30 \mathrm{kA}, 0.5 \mu \mathrm{s})$ are being investigated for materials processing. Demonstrated and potential applications include film deposition, glazing and joining, alloying and mixing, cleaning and polishing, corrosion improvement, polymer surface treatments, and nanophase powder synthesis. Initial experiments at Los Alamos have emphasized thin-film formation by depositing beam ablated target material on substrates. We have deposited films with complex stoichiometry such as $\mathrm{YBa}_{2} \mathrm{Cu}_{3} \mathrm{O}_{7-x}$ and formed diamond-like-carbon films. Instantaneous deposition rates of $1 \mathrm{~mm} / \mathrm{sec}$ have been achieved because of the short ion range(typically $1 \mu \mathrm{m}$ ), excellent target coupling, and the inherently high energy of these beams. Currently the beams are produced in single shot uncomplicated diodes with good electrical efficiency. High-voltage modulator technology and diodes capable of repetitive firing, needed for commercial application. are being developed.
\end{abstract}

Typeset using REVTEX 


\section{INTRODUCTION}

Intense pulsed ion beams have been extensively studied as a driver for inertial confinement fusion [1]. That effort continues to this day. More recently, intense pulsed ion beams (100-1000 keV, 10-100 kA, 0.2-1 $\mu \mathrm{s}$ ) have been applied to the processing of materials. These beams offer the potential to produce advanced and novel materials, to replace existing processes at lower cost, and to replace existing processes with more environmentally benign ones.

Sustained efforts to investigate ion beam processing of materials have begun in Russia, Japan, and, more recently, the United States. Demonstrated and potential applications include film deposition [2-8], glazing and joining [9], alloying and mixing [10-13], cleaning and polishing $[9,14,15]$, corrosion improvement $[9,10]$, improving wear resistance $[10,14]$, improving microhardness $[9,10,14,15]$, polymer surface treatment, and nanophase powder synthesis.

\section{BEAM GENERATION}

The ion source for the great majority of the work on intense ion beam processing of materials has been the high-power, magnetically insulated diode (MID). A theoretical description of the operation of high power ion diodes has been given by Desjarlais [16], and has been found to predict very well the operating characteristics of a large number of ion diodes. In particular, the work presents an explanation for the observed fact the ion current in high-power MID's typically exceeds the Child-Langmuir space charge limited current by a large factor (5-20 times). Here we present only a brief, qualitative description of MID operation and refer the interested reader to the previously mentioned reference. Figure 1 shows the diode and magnetic insulation presently in use on the Anaconda accelerator at Los Alamos National Laboratory.

In this diode, a fast (200 $\mu$ s risetime) magnetic field of $5 \mathrm{kG}$. transverse to the $3 \mathrm{~cm}$ 
anode-cathode $(\mathrm{A}-\mathrm{K})$ gap, is produced by driving a current through the insulating field coils. When this field is at its peak, a high voltage pulse $(300-400 \mathrm{kV})$, produced by the Anaconda Marx generator, is applied to the anode. Tangential electric fields and electron losses to the anode cause the surface of the lucite anode insert to flashover, forming an anode plasma from which ions can be extracted. The insulating magnetic field prevents the electric field from accelerating electrons across the A-K gap, but the much more massive ions are practically unaffected by the magnetic field and are accelerated by the high voltage pulse. The diode shown in Figure 1 is configured to produce a ballistic focus of the ions about $30 \mathrm{~cm}$ downstream from the diode.

Figure 2 shows voltage and current waveforms from the Anaconda accelerator, along with ion current as measured by a magnetically insulated charge collector. Pulse parameters vary somewhat from shot to shot, but typical values are $300-400 \mathrm{kV}$ for the peak voltage, $30-40 \mathrm{kA}$ for the peak ion current, and $0.5-1.0 \mu$ s for the ion current duration. The time needed for the lucite insert to flashover and become an ion source causes the delay between the beginning of the voltage and current waveforms. Ion current is probably terminated by plasma motion along magnetic field lines. In Figure 2, this occurs well before the end of the current pulse. Recent advances at Los Alamos have extended the ion current pulse duration to as long as $1.5-2.0 \mu \mathrm{s}$.

Other experiments at Los Alamos have measured the beam composition and mapped out the energy deposited by the beam using thermal imaging. Ion beam composition was measured with a Thomson parabola spectrometer. Beam composition was found to be $20 \%$ $\mathrm{H}^{+}, 40 \% \mathrm{C}^{+}$and $\mathrm{C}^{++}$, and $40 \% \mathrm{O}^{+}$and $\mathrm{O}^{++}$. A thermal imaging calorimeter was used to obtain spàtially resolved information about energy deposited by the beam. The calorimeter consisted of a thin $(0.62 \mathrm{~mm})$ titanium target, placed in the path of the ion beam, and viewed from behind with an infrared camera (Inframetrics Model 600). Beam energy deposited on the front side of the target was calculated from the heat capacity of the target and the observed temperature rise on the back side. In order to perform this measurement at positions where the beam intensity was sufficient to vaporize target material. the beam was 
apertured and allowed to expand before striking the calorimeter. An integration over the area of the target was then performed to find the total beam energy passing through the aperture. A peak energy density of $30 \mathrm{~J} / \mathrm{cm}^{2}$ on axis was observed in this manner $[17,18]$.

A diode such as the one shown in Figure 1 is inherently a single shot device. The surface of the lucite anode insert is vaporized by each shot, and the gas load created by the vaporized material requires many seconds to be evacuated from the treatment chamber. More advanced diode designs. capable of repetitive operation and designed expressly for materials treatment experiments, are described in section V.

\section{PULSED ION BEAM DEPOSITION}

Two main methods of materials treatment have been identified. One, pulsed ion beam deposition, is discussed in this section, while the other, ion beam surface treatment, is discussed in the section that follows. Both processes utilize the ion beam simply as a flash heat source. Chemical reaction or implantation of the beam ions is not believed to play an important role in either case.

Pulsed ion beam deposition is depicted schematically in Figure 3. The process is akin to pulsed laser deposition. An intense, pulsed, ion beam is focused onto a target, heating an ion range (typically about $1 \mu \mathrm{m}$ ) of material above the vaporization threshold. The vaporized material expands in a plume normal to the surface of the target, and is condensed onto a substrate as a thin film. Compared to pulsed laser deposition, the process offers advantages both because the ion beam is more efficient and less expensive to generate and because the ions couple their energy efficiently into all kinds of targets, including metals.

Work at Los Alamos has concentrated on the growth of two thin films, $\mathrm{YBa}_{2} \mathrm{Cu}_{3} \mathrm{O}_{7-x}$ (1-2-3) and diamond like carbon (DLC). 1-2-3 films were produced by vaporizing a pressed powder target, which ordinarily would melt incongruently. Rutherford backscattering analysis of the $\mathrm{YBa}_{2} \mathrm{Cu}_{3} \mathrm{O}_{7-x}$ film indicated that the complex stoichiometry of the target was preserved to within 10\%, as shown in Figure $4[19,20]$. 
Pulsed ion beam deposited DLC films have been studied extensively at Los Alamos [2]. Deposition rates of $20-50 \mathrm{~nm}$ per pulse were observed, yielding an instantaneous deposition rate of more than $1 \mathrm{~mm} / \mathrm{sec}$. Resistivities between 1 and $1000 \Omega \mathrm{cm}$ were measured, with lower resistivities being obtained for smaller $(150 \mathrm{~mm})$ target/substrate separations and substrate positions normal to the target. Resistivities increased with target/substrate separation and with angular offset of the substrate from the target normal. Raman spectra, shown in Figure 5, indicate an increasing diamond like character for larger target/substrate separations and larger angular offsets from the target normal. Electron field emission data are shown in Figure 6. The films display high electron emission characteristics and obey Fowler-Nordheim scaling.

Pulsed ion beam deposition studies continue at many other laboratories around the world. In Russia, boron nitride and aluminum oxide films have been depositied [3], as well as cadmium, lead, zinc, and brass films [4]. In Japan, electroluminescent ZnS:Mn films, ${ }^{10} \mathrm{~B}$ films for thermal neutron detection, Yttria stabilized Zirconia films, and apatite (calcium phosphate) films have all been formed by pulsed ion beam deposition [6]. Experiments to deposit CdTe for photovoltaic cells will begin shortly at Los Alamos.

\section{ION BEAM SURFACE TREATMENT?}

Ion BEam Surface Treatment (IBEST) is depicted schematically in Figure 7. In this process, an intense ion beam brings the temperature of a surface layer (about an ion range deep) of the target above the melting point. Thermal diffusion is minimized by employing a short pulse (500 ns or less, depending on the thermal conductivity of the target material). Rapid resolidification of the target material produces amorphous layers, dissolves precipitates, and forms non-equilibrium microstructures. IBEST experiments led by Sandia National Laboratories, and performed there, at Cornell University, and at Los Alamos have demonstrated a threefold increase in the hardness of $\mathrm{O} 1$ tool steel, more than a sixfold increase in the pitting time of 2024-T3 aluminum alloy, and a decrease in surface roughness of Ti-6 Al-4V 
from $5 \mu \mathrm{m}$ to $0.1 \mu \mathrm{m}[9]$.

\section{TECHNOLOGY DEVELOPMENT}

Two important developments are paving the way for commercial scale application of intense ion beams to materials processing. One is the emergence of an active anode plasma source, which provides uniform, reproducible anode plasmas of controllable composition, and is inherently capable of high $(100 \mathrm{~Hz})$ repetition rates. The other is the combining of this active anode technology with a suitable pulsed power system to yield a high repetition rate ion beam system.

The new active anode is known as a Magnetically confined Anode Plasma (MAP) source [21-23], developed by John Greenly of Cornell University's Laboratory of Plasma Studies. The MAP ion source uses a fast rising magnetic field to ionize a gas puff and to stagnate the ionized gas against the diode insulating field, where the ionized gas acts as a plasma anode. MAP diodes are being deployed at Los Alamos and Sandia National Laboratories for materials processing studies.

One of us (RWS) is leading an effort by researchers at Sandia National Laboratories, Albuquerque, to pair the MAP diode to a repetitive pulsed power system to yield an ion beam treatment machine capable of operating at commercially relevant levels. The completed machine is expected to produce ions with greater than $250 \mathrm{keV}$ energies and operate at or above the $30 \mathrm{~kW}$ average power level with greater than $30 \%$ energy efficiency, wall plug to material.

\section{SUMMARY}

Intense ion beams have already demonstrated great promise in the preparation of novel and advanced materials with desirable electronic, chemical and mechanical properties. With the emergence of a high repetition rate capability for generating these beams. the potential both for bringing new processes to industry and for replacing existing processes with more 
economical and more environmentally benign ones can be realized. Much more work on process development and understanding the science of ion beam treated materials is required, however, before the possibilities presented by ion beam treatment of materials can be brought to fruition.

\section{ACKNOWLEDGEMENTS}

This work was supported by the U. S. Department of Energy, under contract number W-7405-ENG-36, through Los Alamos National Laboratory, Laboratory Directed Research and Development. One of us (JCO) was supported by the Director's Office of Los Alamos National Laboratory through a Director's Funded Postdoctoral Fellowship.

The authors are grateful to Carlos Ruiz and Al Schmidlapp of Sandia National Laboratories, Albuquerque, for assistance with the Thomson Parabola measurements. The authors are also grateful to Jeff Espinosa and James Lopez for their assistance in conducting experiments at Los Alamos National Laboratory. 


\section{REFERENCES}

[1] J. VanDevender and D. Cook, Science 232, 831 (1986).

[2] G. P. Johnston et al., Journal of Applied Physics 76, 5949 (1994).

[3] A. N. Zakoutayev. G. E. Remnev, and I. F. Isakov, in Proceedings of the Tenth International Conference on High-Power Particle Beams(NTIS PB95-144317), edited by W. Rix and R. White (National Technical Information Service, Springfield, VA, 1994).

[4] I. F. Isakov, G. E. Remnev, and A. N. Zakutayev, in Proceedings of the Ninth International Conference on High-Power Particle Beams(NTIS PB92-206168), edited by D. Mosher and G. Cooperstein (National Technical Information Service, Springfield, VA, 1992), pp. 1966-1970.

[5] A. Kitamura, T. Asahina, Y. Furuyama, and T. Nakajima, in Proceedings of the Ninth International Conference on High-Power Particle Beams(NTIS PB92-206168) (National Technical Information Service, Springfield, VA, 1992), pp. 976-981.

[6] T. Sonegawa et al., in Proceedings of the Ninth International Conference on High-Power Particle Beams(NTIS PB92-206168), edited by D. Mosher and G. Cooperstein (National Technical Information Service, Springfield, VA, 1992), pp. 1971-1976.

[7] O. I. Goncharov et al., in Proceedings of the Eighth International Conference on HighPower Particle Beams (World Scientific, Teaneck, NJ, 1990), pp. 1243-1248.

[8] K. Masugata et al., in Proceedings of the Eighth International Conference on High-Power Particle Beams (World Scientific, Teaneck, NJ, 1990), pp. 1254-1260.

[9] R. W. Stinnett et al.. in .Materials Synthesis and Processing using Ion Beams, Vol. 316 of IIRS Symposium Proceedings, edited by R. J. Culbertson, O. W. Holland. K. S. Jones, and K. Maex (Materials Research Society, Pittsburgh, PA, 1994).

10] A. D. Pogrebnjak. G. E. Remnev, I. B. Kurakin, and A. E. Ligachev. Nuclear Instru- 
ments and Methods in Physics Research B 36, 286 (1989).

[11] R. Fastow et al., Journal of Vacuum Science and Technology A 5, $2 \$ 42$ (1987).

[12] R. Fastow et al., Journal of Vacuum Science and Technology A 5, 164 (1987).

[13] R. Fastow and J. W. Mayer, Journal of Applied Physics 61, 175 (1987).

[14] G. E. Remnev et al., in Proceedings of the Tenth International Conference on HighPower Particle Beams(NTIS PB95-144317), edited by W. Rix and R. White (National Technical Information Service, Springfield, VA, 1994).

[15] G. Remnev and V. Shulov, in Proceedings of the Ninth International Conference on High-Power Particle Beams(NTIS PB92-206168), edited by D. Mosher and G. Cooperstein (National Technical Information Service, Springfield, VA, 1992), pp. 365-372.

[16] M. Desjarlais, Physics of Fluids, B 1, 1709 (1989).

[17] H. A. Davis, R. R. Bartsch, D. J. Rej, and W. J. Waganaar, in Proceedings of the Tenth International Conference on High-Power Particle Bearns(NTIS PB95-144317), edited by W. Rix and R. White (National Technical Information Service, Springfield, VA, 1994).

[18] H. A. Davis et al., in Proceedings of the Tenth International Conference on High-Power Particle Beams(NTIS PB95-144317), edited by W. Rix and R. White (National Technical Information Service, Springfield, VA, 1994).

[19] D. J. Rej et al., in Proceedings of the Ninth International Conference on High-Power Particle Beams(NTIS PB92-206168), edited by D. Mosher and G. Cooperstein (National Technical Information Service, Springfield, VA, 1992), pp. 88-95.

[20] D. C. Gautier et al., Technical Report No. LA-12499-PR, Los Alamos National Laboratory (unpublished).

[21] J. B. Greenly et al., in Proceedings of the Eighth International Conference on High- 
Power Particle Beams (World Scientific, Teaneck, NJ, 1990), pp. 199-206.

[22] M. Leda, J. B. Greenly, G. D. Rondeau. and D. A. Hammer, The Review of Scientific Instruments 64, 2737 (1993).

[23] J. B. Greenly, M. Ueda, G. D. Rondeau, and D. A. Hammer, Journal of Applied Physics 63, 1872 (1988). 


\section{FIGURES}

FIG. 1. The Anaconda magnetically insulated diode. Surfaces of level magnetic flux are superimposed.

FIG. 2. Typical voltage, machine current, and ion current for Anaconda ion beam shots.

FIG. 3. Schematic depiction of pulsed ion beam deposition. An intense ion beam is directed at a target. The beam vaporizes an ion range of material, which expands normally to the target. The vaporized material is deposited as a thin film on a substrate.

FIG. 4. RBS profile of a Y-Ba-Cu-O film deposited on Si by pulsed ion beam deposition. [19]

FIG. 5. Raman spectra of films deposited at: (A) substrate/target separation of $150 \mathrm{~mm}$ and normal to the target; (B) substrate/target separation of $150 \mathrm{~mm}$ and $50^{\circ}$ off normal; (C) substrate/target separation of $225 \mathrm{~mm}$ and normal to the target [2].

FIG. 6. (A) Field-emission current vs. voltage using a $2 \mathrm{~mm}$ ball probe at $30 \mu \mathrm{m}$. (B) Fowler-Nordheim plot of data from (A). [2]

FIG. 7. Schematic depiction of ion beam surface treatment. An intense beam is directed at a target. The beam melts an ion range of material, which cools rapidly through thermal diffusion into the unheated bulk materials. Novel material structures can be formed in the treated layer. 


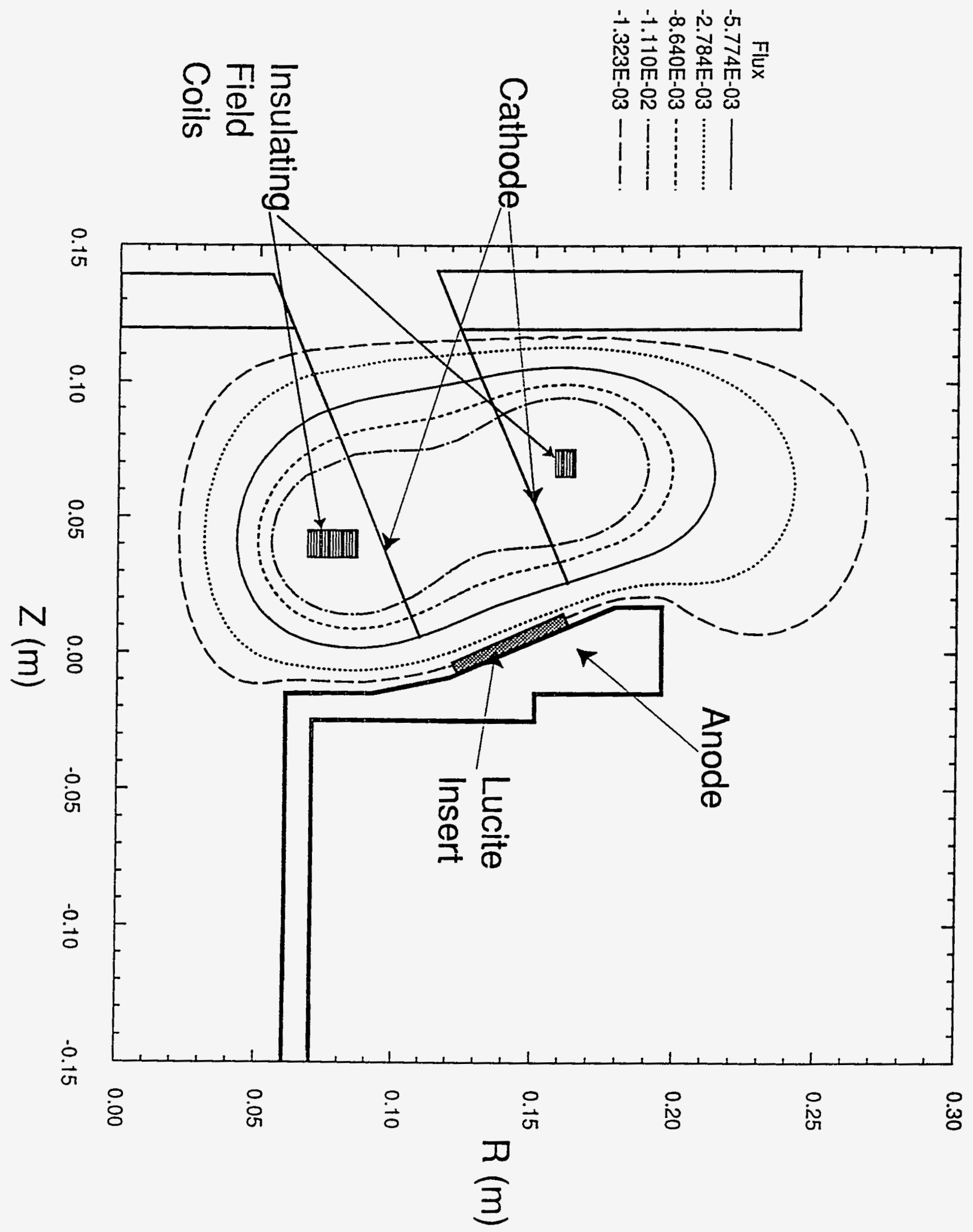

Figure 1 


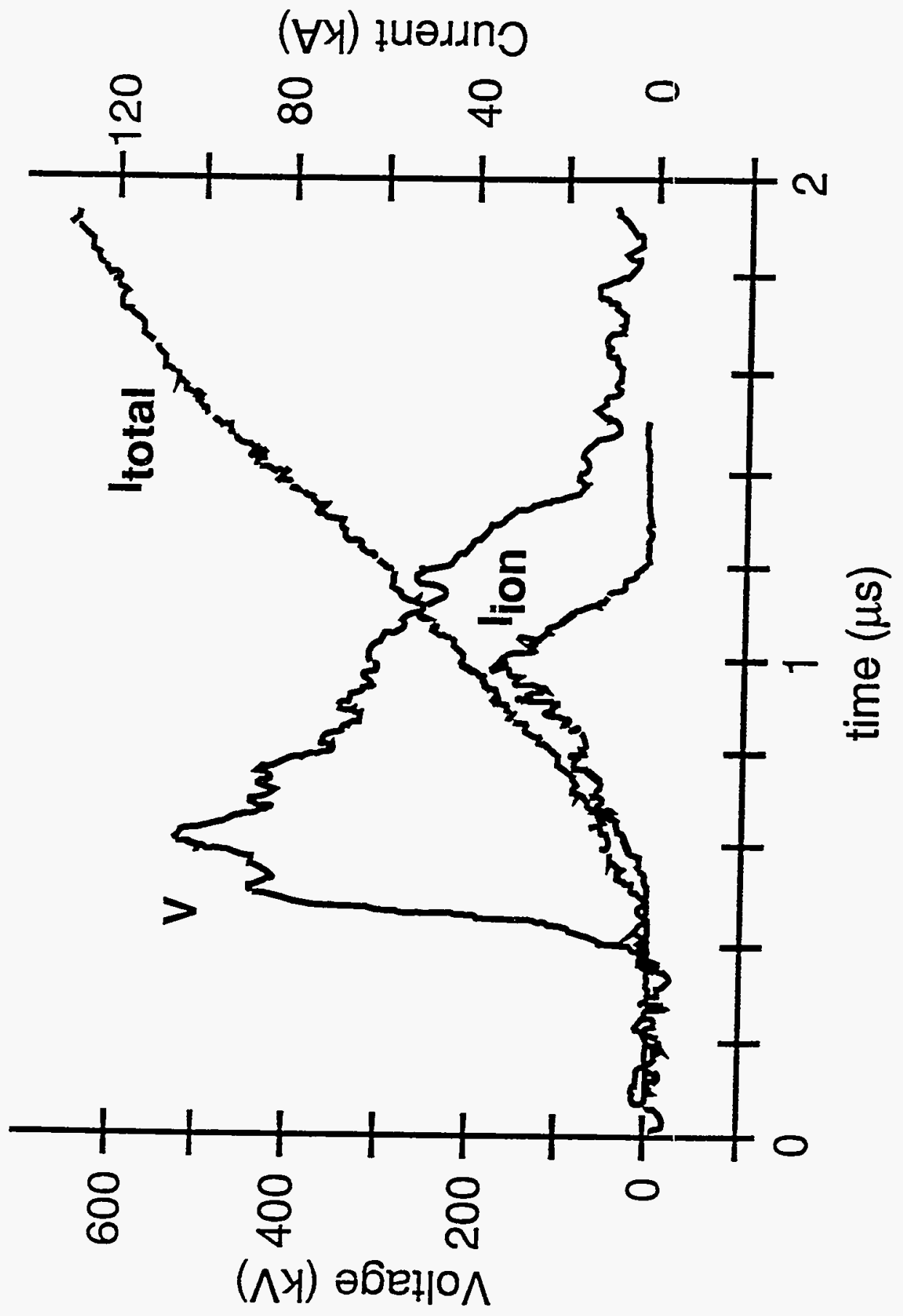

Figure 2 


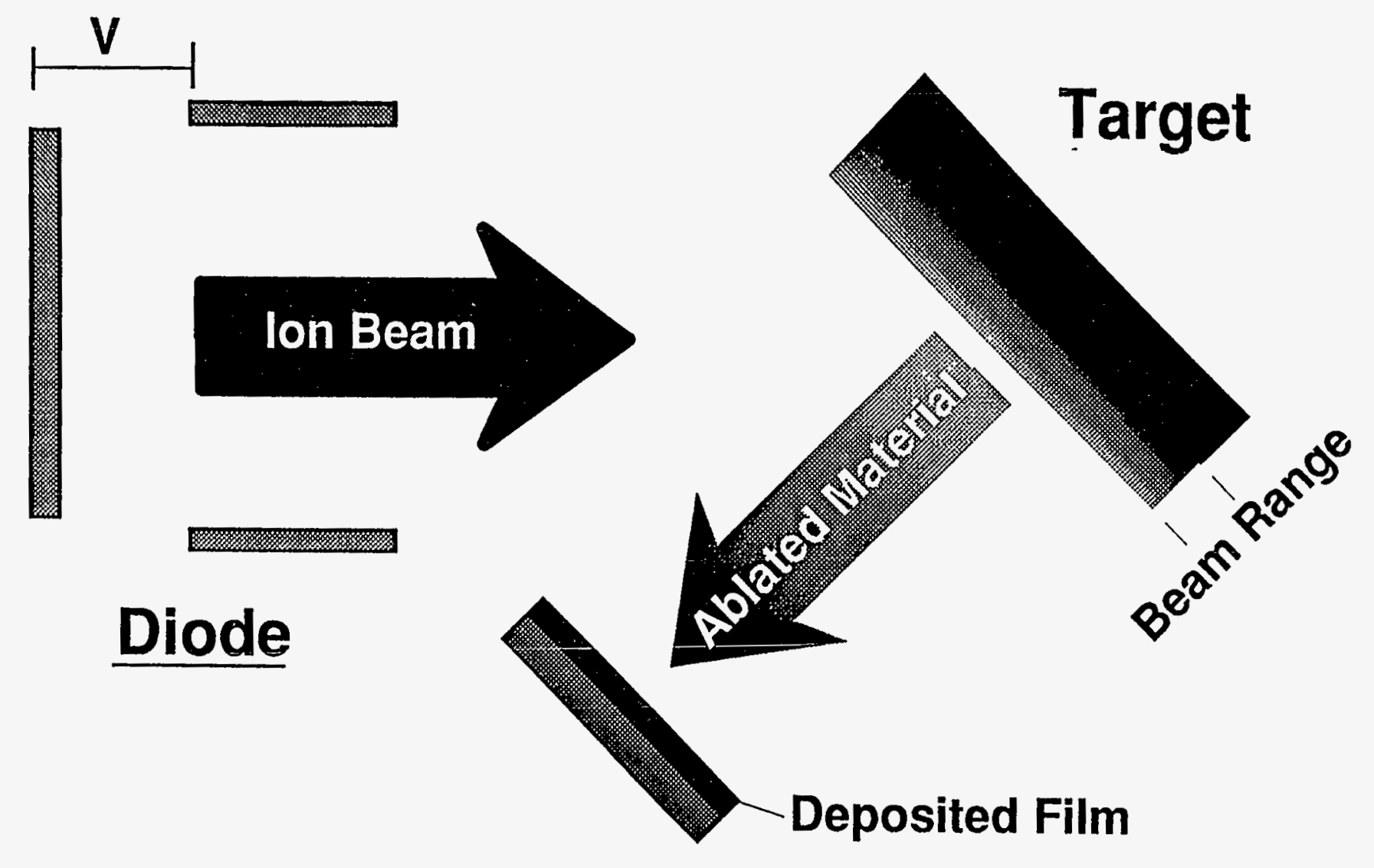

0

Substrate 


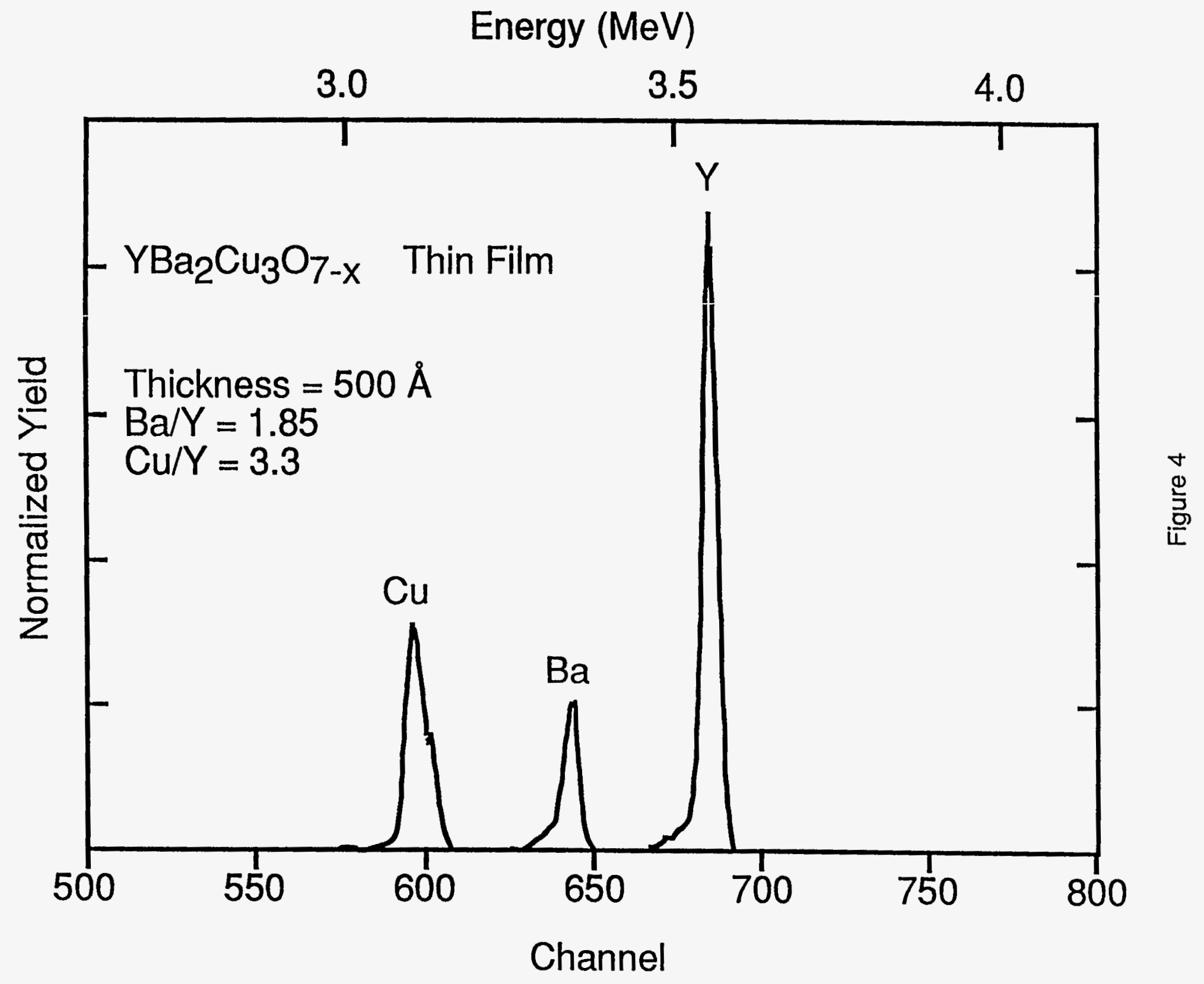




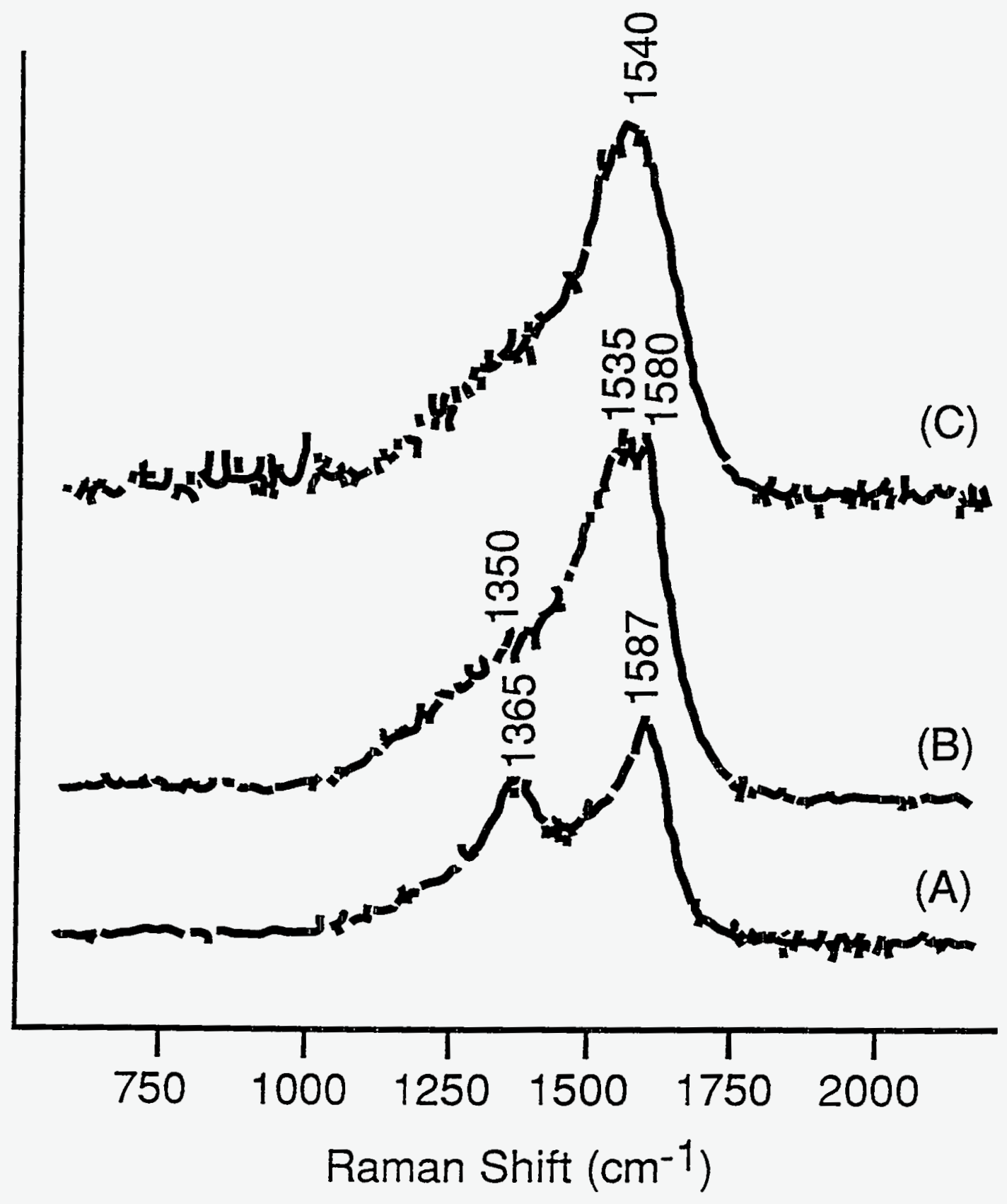

Figure 5 

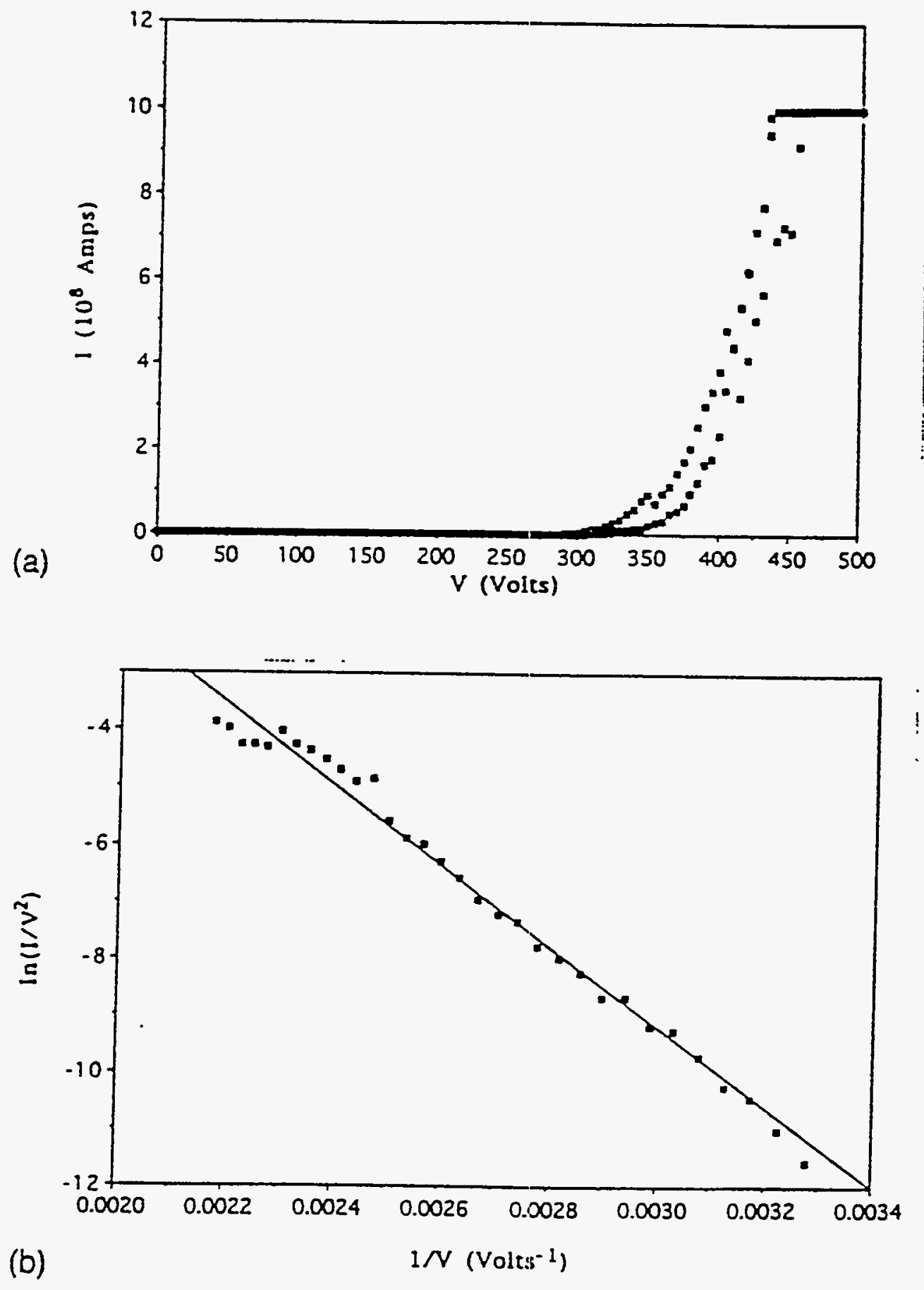

Figure 6 

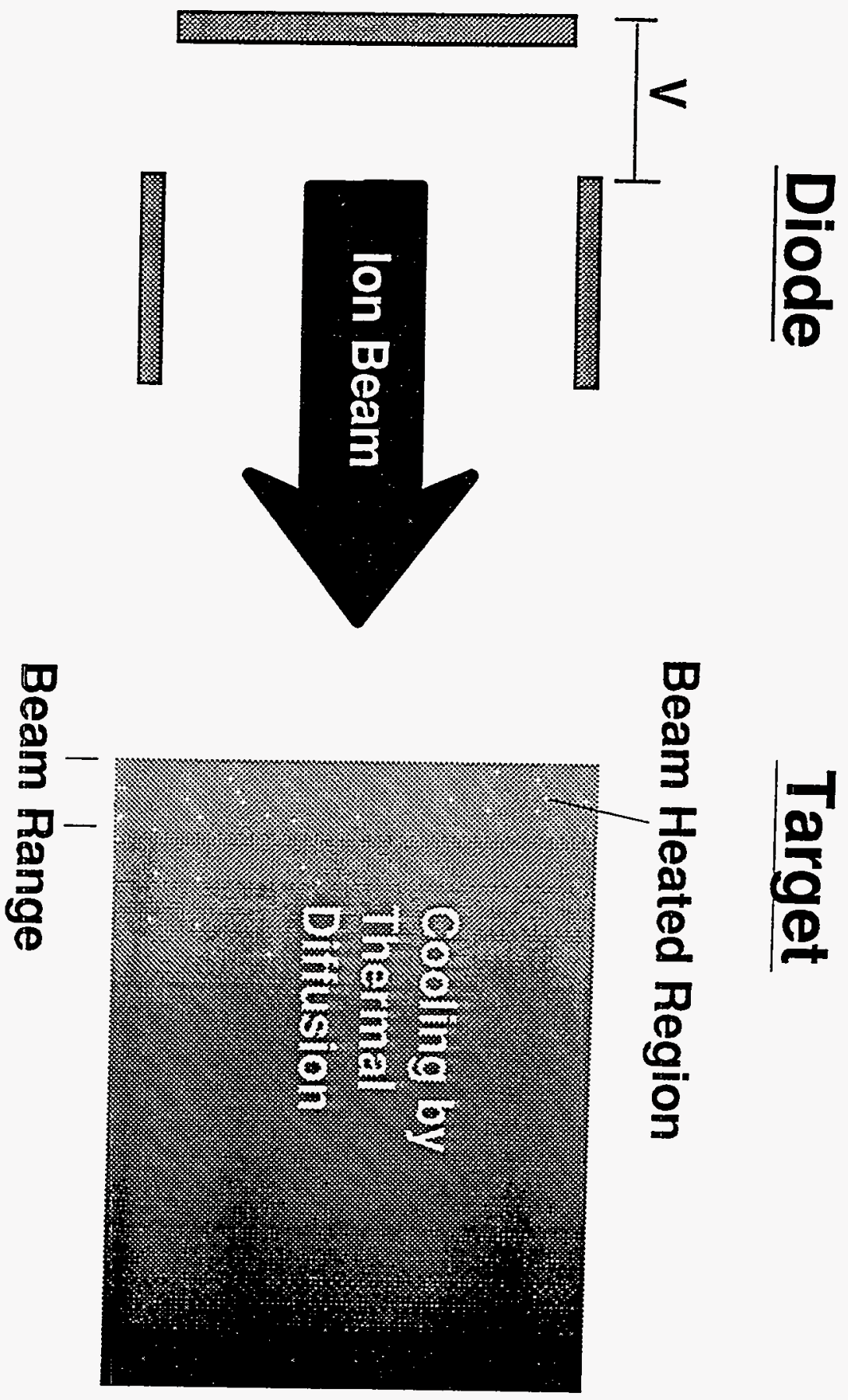

Figure 7 